\title{
Enhancement of the pool boiling heat transfer coefficient using the gas injection into the water
}

\author{
M.M. Sarafraz ${ }^{*}$, S.M. Peyghambarzadeh ${ }^{2}$, S.A. Alavi Fazel ${ }^{3}$ \\ ${ }^{1}$ Islamic Azad University, Department of Chemical Engineering, Mahshahr Branch, Mahshahr, Iran \\ ${ }^{2}$ Islamic Azad University, Department of Chemical Engineering, Mahshahr Branch, Mahshahr, Iran \\ ${ }^{3}$ Islamic Azad University, Department of Chemical Engineering, Mahshahr Branch, Mahshahr, Iran \\ * Corresponding author: e-mail: mohamadmohsensarafraz@gmail.com
}

\begin{abstract}
In this paper, a new method for enhancing the pool boiling heat transfer coefficient of pure liquid, based on the gas injection through the liquids has been introduced. Hence, the effect of gas dissolved in a stagnant liquid on pool boiling heat transfer coefficient, nucleation site density, and bubble departure diameter has experimentally been investigated for different mole fractions of $\mathrm{SO}_{2}$ and various heat fluxes up to $114 \mathrm{~kW} / \mathrm{m}^{2}$. The presence of $\mathrm{SO}_{2}$ in captured vapor inside the bubbles, particularly around the heat transfer surface increases the pool boiling heat transfer coefficient. The available predicted correlations are unable to obtain the reasonable values for pool boiling heat transfer coefficient in this particular case. Therefore, to predict the pool boiling heat transfer coefficient accurately, a new modified correlation based on Stephan-Körner relation has been proposed. Also, during the experiments, it is found that nucleation site density is a strictly exponential function of heat flux. Accordingly, a new correlation has been obtained to predict the nucleation site density. The major application of the nucleation site density is in the estimating of mean bubble diameters as well as local agitation due to the rate of bubble frequency.
\end{abstract}

Keywords: Heat transfer, Pool boiling, Gas-liquid solution, Nucleation site density, $\mathrm{SO}_{2}$, water.

\section{INTRODUCTION}

Pool boiling has long played a major role in many technological applications due to its superior heat transfer performance. The complexities encountered in the boiling process have stimulated numerous investigators to conduct extensive research in this field. Because of unknown properties which are hidden inside the boiling phenomenon, many investigators have done lots of experiments on different substances. This complexity is due to the heterogeneous nature of heat transfer medium. Boiling of liquid mixtures is furthermore integrated with a simultaneous heat and mass transfer between vapor inside the bubble and the vapor/liquid interface, which makes the phenomenon much more complicated. So far, the boiling phenomenon has not been modeled through any simple theoretical model. This is due to the impact of some additional complicated sub-phenomena including the nucleation site density, bubble departure diameter and bubble generation frequency, which provides a sophisticated modeling route. Until now, many predictive empirical correlations for boiling heat transfer coefficient in pure liquids have been proposed. Vinayak-Balakrishnan $^{1}$ has a comprehensive survey on some correlations including Gorenflo ${ }^{2}$, Stephan-Abdelsalam ${ }^{3}$ and McNelly ${ }^{4}$. The applicability and reliability of some other correlations such as Boyko-Kruzhilin ${ }^{5}$ and Mostinski ${ }^{6}$ could be found in some other sources ${ }^{7-10}$. Gorenflo model as a major distinction along with other correlations, which is the presence of two tuning parameters. This tuning parameter, $n, F_{W M}$, is broadly defined for different pure boiling systems, and could be empirically determined using physical properties. Stephan-Abdelsalam ${ }^{3}$ is also known to be one the best proposed empirical correlations. This correlation has no tuning parameter, so it is applicable to all boiling liquids. A summary of some selected existing correlations for pure boiling systems are given in Table 1 .

In Table 2 some of the well-known correlations for the prediction of pool boiling heat transfer coefficient of binary mixtures have been summarized:

In this table, the ideal heat transfer coefficient, $\alpha_{i d}$ has been defined as follows:

$\frac{1}{\alpha}=\frac{1}{\alpha_{i d}}=\sum_{i=1}^{N} \frac{x_{i}}{\alpha_{i}}$

In this work, the influence of gas injection on enhancing the pool boiling heat transfer has been experimentally investigated. Due to the importance of heat transfer coefficient in designing the heat transfer tools and heat exchangers particularly those of working in saturation temperatures, higher heat transfer rates may help the designers to obtain the economic designs. Therefore, several methods for enhancing the heat transfer coefficient have recently been examined. Nanofluids, Ultrasonic waves, surfactants, surfaces with high roughness are samples of an enhancing method that has been investigated. In this research, the effect of gas dissolved into the water has been experimentally tested. Many experiments have been performed to investigate the effect of the gas dissolved on boiling sub-phenomena such as bubble diameter, nucleation site density and the pool boiling heat transfer coefficient.

\section{EXPERIMENTAL:}

\section{Experimental setup}

Fig. 1 presents schematically the experimental equipment used in the present experiments. This boiling vessel is a vertical hollow cylinder of stainless steel containing approximately 30 liters of the test liquid connected to a 
Table 1. Available correlation for heat transfer coefficient in pure liquids

\begin{tabular}{|c|c|c|}
\hline Author & Correlation & Ref. \\
\hline Gorenflo & $\begin{array}{c}\alpha=\alpha_{0} F_{q} F_{P} F_{W R} F_{W M} \text { (1) } \\
F_{q}=\left(\frac{q}{q_{0}}\right)^{n} \quad \text { where } \quad n=0.9-0.3 P_{r}^{0.3} \\
F_{p}=1.2 P_{r}^{0.27}+2.5 P_{r}+\frac{P_{r}}{1-P_{r}} \quad ; \quad F_{W R}=\left(\frac{R_{a 0}}{R_{a}}\right)^{\frac{2}{15}} \\
F_{W M}=\left(\frac{k \rho C}{k_{0} \rho_{0} C_{0}}\right)^{\frac{1}{4}} ; \quad q_{0}=20 \frac{\mathrm{kW}}{\mathrm{m}^{2}}\end{array}$ & [2] \\
\hline $\begin{array}{l}\text { Stephan- } \\
\text { Abdelsalam }\end{array}$ & $\alpha=.23 \frac{k_{l}}{d_{b}}\left(\frac{q d_{b}}{A k_{l} T_{s}}\right)^{0.674}\left(\frac{\rho_{v}}{\rho_{l}}\right)^{0.297}\left(\frac{H_{f g} d_{b}^{2}}{\alpha_{l}^{2}}\right)^{0.371}\left(\frac{\alpha_{l}^{2} \rho_{l}}{\sigma d_{b}}\right)^{0.35}\left(\frac{\rho_{l}-\rho_{v}}{\rho_{l}}\right)^{-1.7 \mathrm{z}}$ & [3] \\
\hline McNelly & $\alpha=0.225\left(\frac{q C_{l}}{A H_{f g}}\right)^{0.69}\left(\frac{P k_{l}}{\sigma}\right)^{0.31}\left(\frac{\rho_{l}}{\rho_{v}}-1\right)^{0.33}$ & [4] \\
\hline Boyko-Kruzhilin & $\begin{array}{c}\alpha=0.082 \frac{k_{l}}{l^{*}}\left[\frac{H_{f g} q}{g\left(T_{s}+273\right) k_{l}}\left(\frac{\rho_{v}}{\rho_{l}-\rho_{v}}\right)\right]^{0.7}\left[\frac{\left(T_{s}+273\right) C_{p l} \sigma P}{H_{f g}^{2} \rho_{v}^{2} l^{*}}\right]^{0.3 z} \\
l^{*}=\left[\frac{\sigma}{g\left(\rho_{l}-\rho_{v}\right)}\right]^{0.5}\end{array}$ & [5] \\
\hline
\end{tabular}

Table 2. Some well-known correlations for liquid binary mixtures

\begin{tabular}{|c|c|c|}
\hline Author & Correlation & Reference \\
\hline $\begin{array}{l}\text { Vinayak- } \\
\text { Balakrishnan }\end{array}$ & $\frac{\alpha}{\alpha_{i d}}=\left[\mathbf{1}-\left(\mathbf{|} y-x \mathbf{|} \sqrt{\frac{D_{A B}}{\hat{\alpha}}}\right)\right]$ & [1] \\
\hline $\begin{array}{l}\text { Stephan } \\
\text { and Körner }\end{array}$ & $\alpha=\frac{\alpha_{\text {id }}}{1+A_{0}(y-x)(0.88+0.12 P)}$ & [7] \\
\hline Unal & $\begin{array}{c}\frac{\alpha}{\alpha_{i d}}=\frac{1}{\left[1+\left(b_{\mathbf{2}}+b_{\mathbf{3}}\right)\left(1+b_{\mathbf{4}}\right)\right]\left[1+b_{\mathbf{5}}\right]} \\
b_{\mathbf{2}}=\frac{(1-x) \ln (1.01-x)}{1.01-y}+x \ln \frac{x}{y}+|y-x|^{\mathbf{1 . 5}} \\
\frac{x}{y}=1 \text { for } x=y=\mathbf{0} \\
b_{\mathbf{3}}=0 ; b_{\mathbf{4}}=152 P_{r}^{3.9} b_{\mathbf{5}}=0.92 \mathbf{|} y-\left.x\right|^{0.001} P_{r}{ }^{0.66}\end{array}$ & [8] \\
\hline Calus-Rice & $\frac{\alpha}{\alpha_{i d}}=\frac{1}{\left[1+|y-x|\left(\frac{\hat{\alpha}}{D_{A B}}\right)^{0.5}\right]^{0.7}}$ & [9] \\
\hline Schlünder & $\begin{array}{c}\frac{\alpha}{\alpha_{i d}}=\frac{1}{1+(y-x)\left\{1-\exp \left(\frac{-B_{0} q}{\beta_{l} \rho_{l} H_{f g}}\right)\right\}\left(T_{s 1}-T_{s 2}\right) \Delta T_{i d}} \\
B_{\mathbf{n}}=\mathbf{1} ; \quad \beta_{l}=2 E-4 \frac{\mathrm{m}}{\mathrm{s}}\end{array}$ & [10] \\
\hline
\end{tabular}

vertical condenser to condense and recycle the evaporated liquid. The whole system is heavily insulated for more controllability and reduction of heat loss. To prevent the heating loss under all the circumferences of the test vessel and all the other metal parts of the experimental setup, the two-layer glass wool insulation was employed and was twisted around the test vessel. The temperature of the liquid inside the tank is continuously monitored and controlled at any predetermined set point by a thermal regulator which connects the thermocouples to an appropriate band heater covering the outside of the tank. Also, at the bottom of the vessel there is a narrow mesh tube which is pitted and used for injecting the gas into the liquid phase. The rate of this injection 
has been controlled by a mass flow controller which has been made by Brooks Industrial Company. The pressure of the system is monitored and regulated continuously. A safety pressure relief valve is also installed to prevent any dangerous situation. The test section is a horizontal rod heater with a diameter of $21 \mathrm{~mm}$ and a heating length of $105 \mathrm{~mm}$ which can be observed and photographed through the observation glasses. This heater consists of an internally heated stainless steel sheathed rod and 14 (fourteen) stainless steel sheathed thermocouples which are entrenched along the circumference of the heater for better recording of the temperature, close to the heating surface. Some details of the rod heater are given in Fig. 2. One thermocouple inside the rod heater was used as a protection trip to cut off the electric power if the temperature exceeds the maximum limit. A PC-based data acquisition system was used to record all the measuring parameters. Data acquisition (Yokogawa MX series) receives the analogue signals of all the thermocouples and voltage/current sensors and converts them to the digital data for using in PC. Also if any short-circuit causes due to any wire loosing, it will shut all the power setup down. The input power to the rod heater is precisely equal to the heat flux and could be calculated by the product of electrical voltage, current and cosine of the difference between electrical voltage and current. The arithmetic average of reading values from the thermocouples around the circumference of cylinder $\left(T_{t h}\right)$ was used as the temperature of surface. To calculate the real surface temperature by correcting the minor temperature drop due to the small distance between surface and thermocouple location, the Fourier's conduction equation is used according to Eq. (2) as follows:

$T_{\text {surface }}-T_{b}=\left(T_{t h}-T_{b}\right)-(s / k)(q / A)$

In this equation, $s$ is the distance between the thermocouple location and the heat transfer surface and $k$ is the thermal conductivity of the heater material. The value of $s / k$ is determined for each thermocouple by the calibration of the test heater. The average temperature difference was the arithmetic average of the four thermocouple locations. The boiling heat transfer coefficient $\alpha$ is calculated by Eq. (3):

$\alpha=\frac{q / A}{\left(T_{\text {sufface }}-T_{b}\right)_{\text {ave }}}$

For each experiment step, the picture of the boiling phenomenon was taken using an ultra-high speed camera. Additionally, to ensure that no $\mathrm{SO}_{2}$ gas has been dissolved into the liquid at saturation temperature and preventing the changing of physical properties due to the solubility of $\mathrm{SO}_{2}$ into the water, two gas flow meters were installed in the path of the entrance and outgoing of the test vessel. These flow meters gauges approximately indicate the similar values that refer to the little amount of water vapors. Furthermore, it is clear that almost all of the injected $\mathrm{SO}_{2}$ comes directly out of the liquid phase.

\section{Experimental procedure}

Initially, the entire system including the rod heater and the tank interior were cleaned and the test solution was introduced. The vacuum pump is then turned on and the pressure of the system is kept low approximately at $10 \mathrm{kPa}$ for five hours to allow all the dissolved gases, especially the dissolved air to be stripped from the test solution. Following this, the tank band heater was switched on and the temperature of the system allowed rising to the saturation temperature. Then the electric power was slowly supplied to the rod heater and increased gradually to a constant predetermined value. The data acquisition system, video equipment including a digital camera was simultaneously switched on to record the required parameters, including the rod heater temperature, bulk temperature, heat flux and also all visual information. All experimental runs were carried out with decreasing the heat flux to eliminate the hysteresis effect. Some runs were repeated more than three times to ensure that the results are valid and no significant error due to the experimental error (reading error and tools uncertainties) is involved in the obtained experimental data as well as the reproducibility of the experiments.

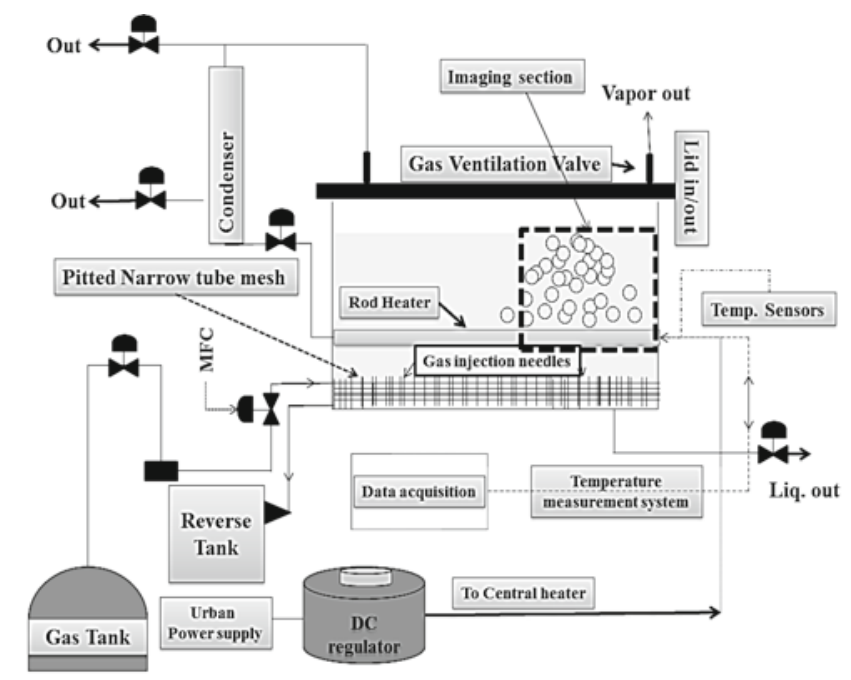

Figure 1. A scheme of the experimental apparatus

Cross Section Area:

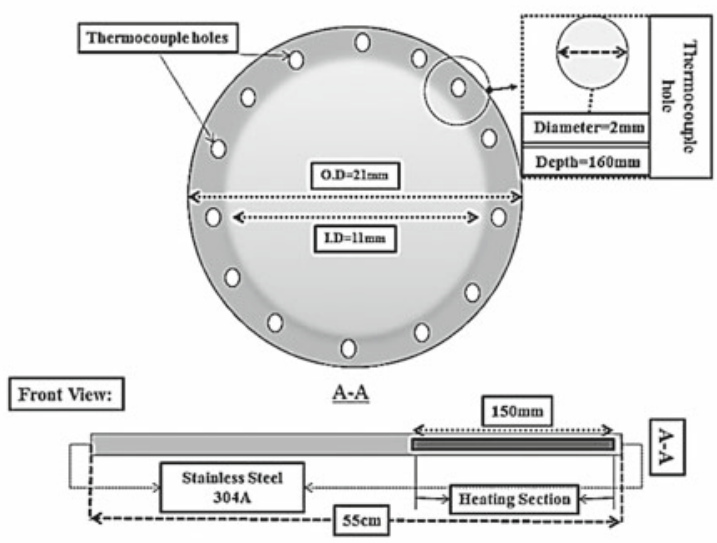

Figure 2a. Some details of the rod heater

Also, a mesh tube has been employed for spreading the gas all over the liquid phase regularly and the injection rate is controlled using the mass flow controller. Fig. 2b shows a scheme of the mesh tube with its characteristic properties: 


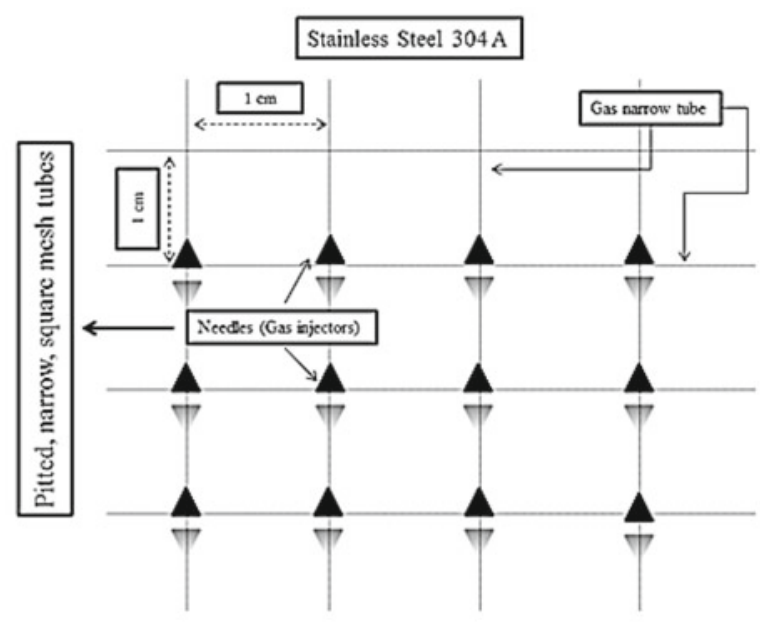

Figure $2 \mathbf{b}$. A scheme of the mesh tube and its design properties

\section{Physical properties of Water/ $\mathrm{SO}_{2}$ :}

The physical properties of $\mathrm{SO}_{2} /$ water have been experimentally measured by a related experimental apparatus. Most of the earlier correlations' bodies consisted of physical properties (see tables $1-2)^{35}$. To estimate the physical properties, for each property, a large number of accurate correlations with the uncertainty lower than $10 \%$ were separated from the other existing correlations in the well-known handbooks ${ }^{25-27}$. Afterwards, each of the physical properties has been measured experimentally by a related experimental apparatus. Accordingly, for the viscosity, a digital viscometer manufactured by Brookfield, for the surface tension a tension-meter (EW59780) manufactured by Cole-Parmer and for the density a density-meter (DDM2910) manufactured by Rudolph Co. were used. The minimum measurement errors of each apparatus were $\pm 1 \%$ of reading, $\pm 2.5 \%$ reading and $1 \%$ reading respectively. For the mass heat of vaporization and heat capacity, a simple calorimeter was used with an experimental measuring error about 3\% (Manufactured by Sarir-Teb Co.). For thermal conductivity, TPS2500S was used with accuracy of $\pm 5 \%$ (claimed by Therm-test Co.). Furthermore, the experimental measured physical properties were used to ensure the accuracy of the estimated values of heat transfer estimating correlations. In fact, the thermo-physical properties of water have also been represented in the well-known handbooks and it is needless to calculate them by predicting the correlations ${ }^{25,27}$. Additionally, the physical properties were measured before and subsequently after the gas injection process to ensure that the presence of gas in the liquid does not change the physical properties of the bulk of the tested fluid. Fig. 3 typically represents the solubility of $\mathrm{SO}_{2}$ in water that is decreased with increasing the temperature to the saturation temperature and it may result in releasing huge amounts of $\mathrm{SO}_{2}$ gas into the liquid phase. On the other hand, it creates a significant mass transfer driving force between the bubble captured vapor and the solution. The bubble captured vapor is confronted against the back diffusion of $\mathrm{SO}_{2}$ from the generated bubbles toward the liquid and subsequently, vapors during the departure become rich in the solute $\mathrm{SO}_{2}$ and result in the artificial enhancement of the bubble departure diameter and enhancement of the nucleate pool boiling heat transfer coefficients. Fig. 4 schematically demonstrates the status of the departing bubbles. Briefly speaking, the local agitation due to the artificial growing of bubbles is considered as a major reason for the increase of heat transfer coefficient around the horizontal cylinder surface.

Fig. 6 shows that increasing the saturation temperature, the liquid viscosity decreases and on the other hand, the thermal conductivity of the solution increases. Similarly

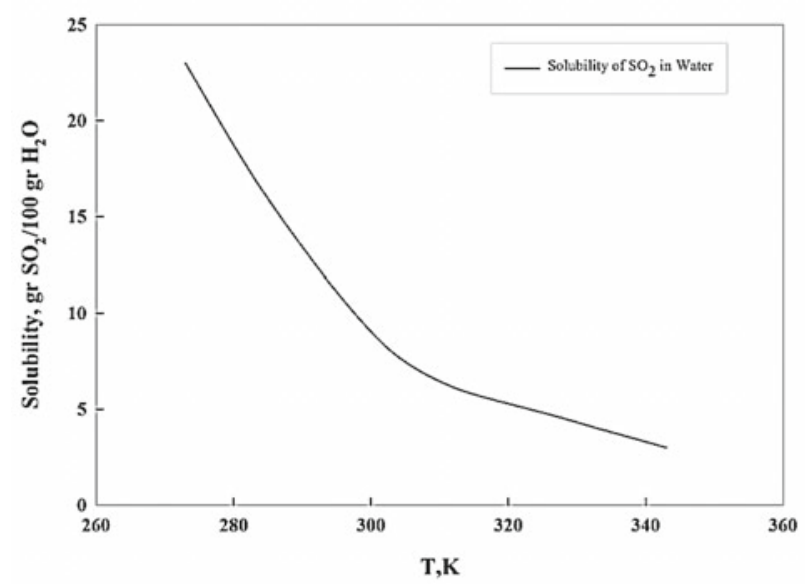

Figure 3. The solubility of $\mathrm{SO}_{2}$ in water at different temperatures

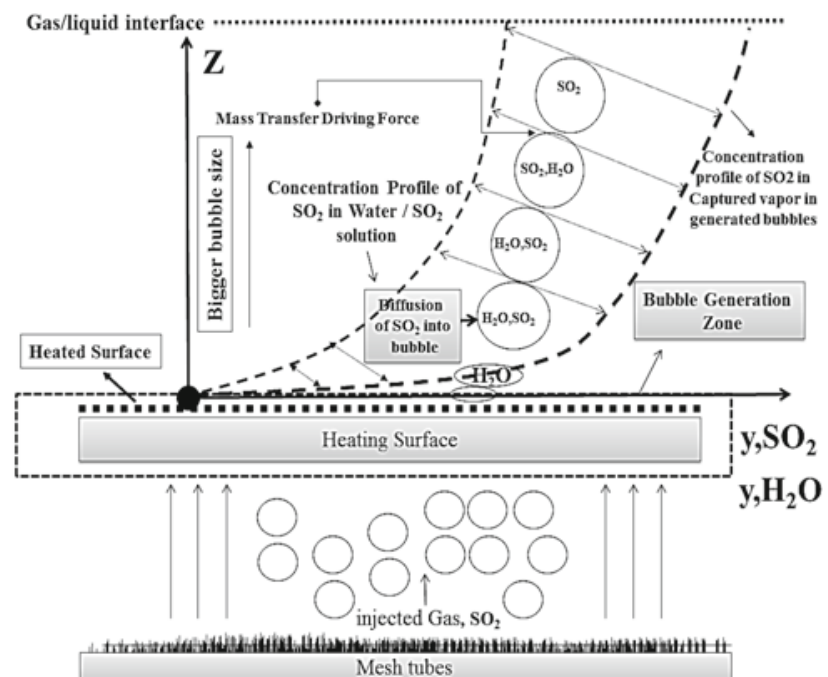

Figure 4. A simplified scheme of Diffusion of $\mathrm{SO}_{2}$ into the water

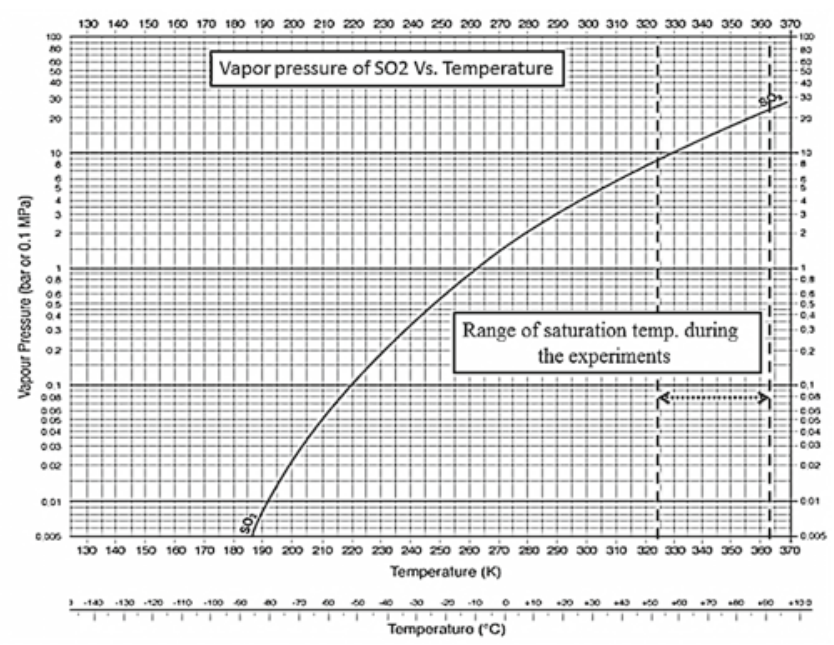

Figure 5. Vapor pressure of $\mathrm{SO}_{2}$ at different saturation temperatures 
to viscosity and thermal conductivity, the surface tension and mass heat of vaporization are changed which has been shown in Fig. 7:

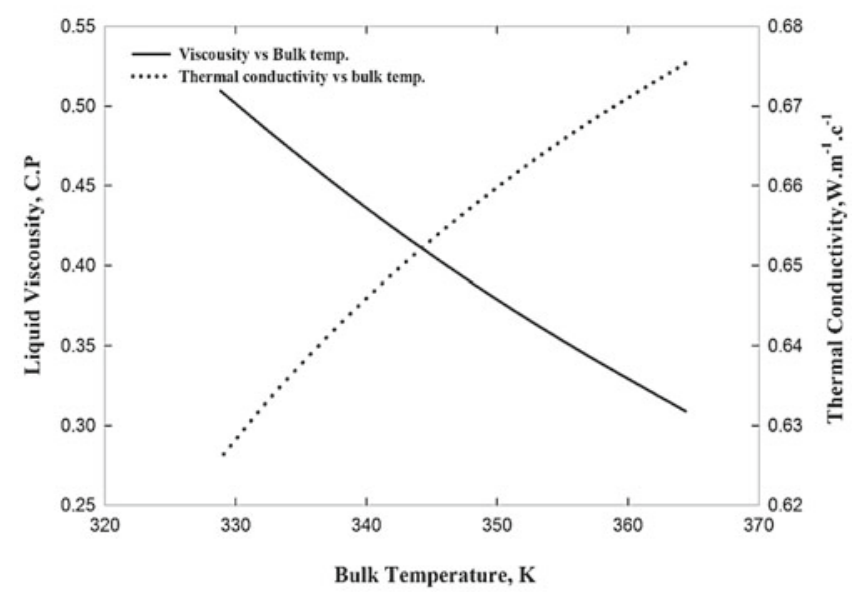

Figure 6. Measured thermal conductivity and viscosity at different saturation temperatures of $\mathrm{SO}_{2}$ /water solutions

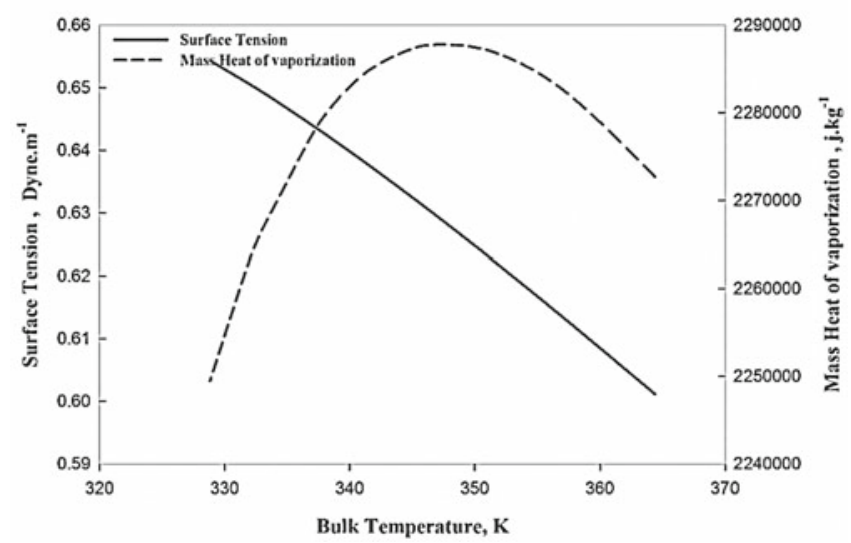

Figure 7. Measured surface tension and mass heat of vaporization at different saturation temperatures of $\mathrm{SO}_{2} /$ water solutions

To determine the phase equilibria of the vapor and liquid phase, Peng-Robinson equation of the state is employed to estimate the mole fraction of $\mathrm{SO}_{2}$ and water through the liquid/vapor phase. Fig. 8 represents the xy equilibrium of $\mathrm{SO}_{2}$ /water through all mole fractions of water and $\mathrm{SO}_{2}$.

An ultra-high-speed camera with a frame rate up to 8000 fps has been used for taking and recording the pictures and videos. The recorded shut, is used later for counting the number of the bubbles and proposing a simple mathematical model for the prediction of the nucleation site density. Figs. 9a and 9b are some instances of the taken pictures.

\section{Uncertainty of experiment:}

To measure the uncertainty of the experiment, a mathematical mean square method has been employed. According to the heat flux estimating correlation:

$q^{\prime \prime}=\frac{V \cdot I}{2 \pi \cdot r_{O} \cdot L}=\frac{W}{2 \pi \cdot r_{O} \cdot L}$

The experimental uncertainty is obtained by the following equation:

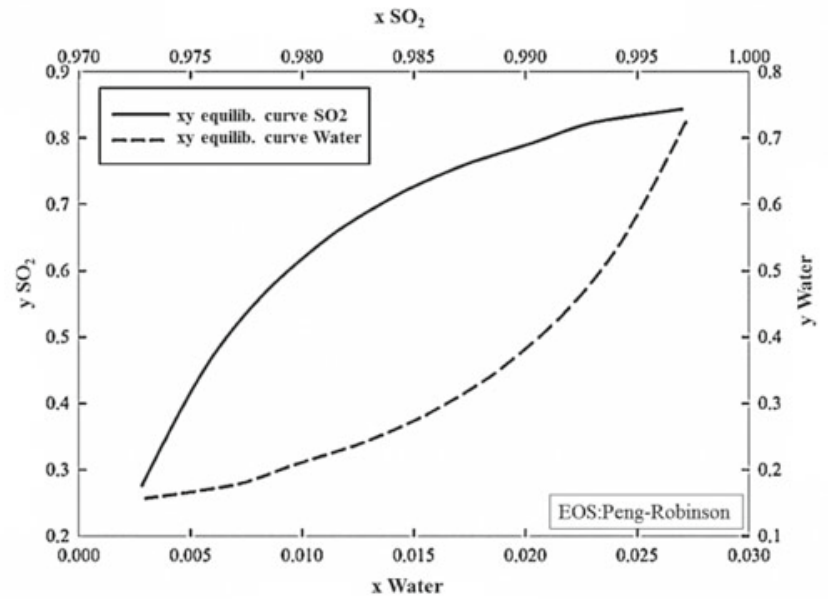

Figure 8. xy equilibrium curve of $\mathrm{SO}_{2} /$ water solutions for all runs of the experiments

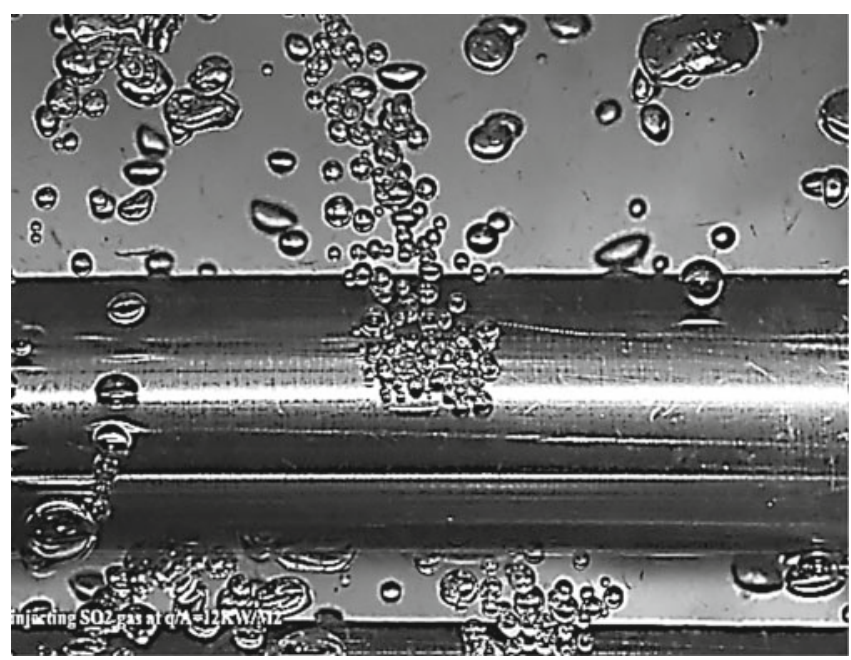

Figure 9a. Bubble generation in pool boiling of $\mathrm{SO}_{2} /$ Water at the heat flux $12 \mathrm{~kW} \cdot \mathrm{m}^{-2}$

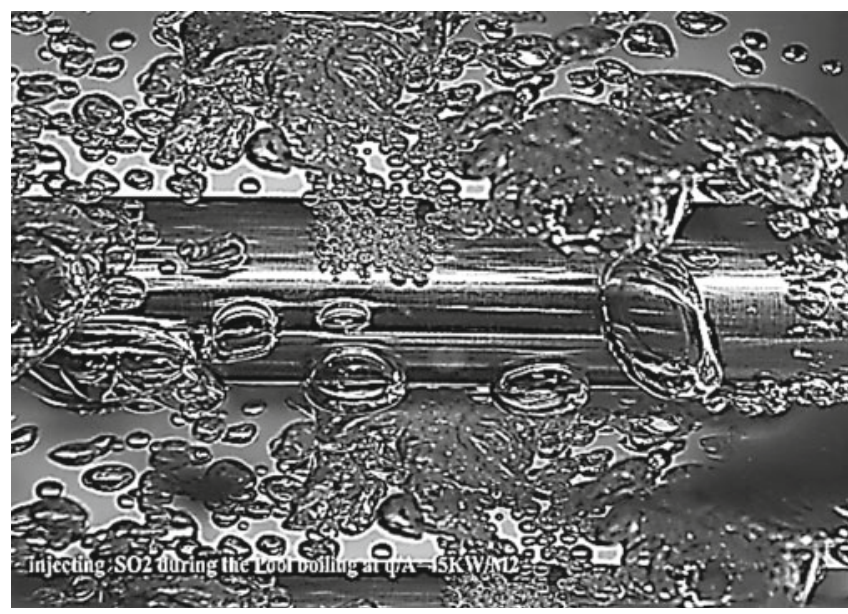

Figure $9 \mathbf{b}$. Bubble generation in pool boiling of $\mathrm{SO}_{2} /$ water at the heat flux $45 \mathrm{~kW} . \mathrm{m}^{-2}$

$\Delta q^{\prime \prime}=\sqrt{\left(\frac{\partial q^{\prime \prime}}{\partial w} \Delta w\right)^{2}+\left(\left(\frac{\partial q^{\prime \prime}}{\partial r} \Delta r\right)\right)^{2}+\left(\frac{\partial q^{\prime \prime}}{\partial L} \Delta L\right)^{2}}$

The values for $\Delta w, \Delta r, \Delta L$ are $8.5,0.3$ and 0.03 respectively.

Accordingly, the pool boiling heat transfer coefficient uncertainty, respect to the obtained $\Delta q$ " by Eq. (6) is obtained by the following equation: 
$\Delta \alpha=\sqrt{\left(\frac{\partial \alpha}{\partial q^{\prime \prime}} \Delta q^{\prime \prime}\right)^{2}+\left(\frac{\partial \alpha}{\partial T} \Delta T\right)^{2}}$

In this research, $\Delta T$ equals to $\pm 0.3^{\circ} \mathrm{C}$ according to the accuracy of each thermocouple and $\Delta q$ " equals to $1.25 \%$ according to Eq. (2) and furthermore, the uncertainty of estimating the heat transfer coefficient equals to \pm $4.8 \%$. Table 3 represents the operational parameters and their ranges.

Table 3. Operational parameters and their ranges

\begin{tabular}{|l|c|c|}
\hline Experimental parameter & Experimental ranges & Unit (SI) \\
\hline Temperature & $328-364$ & $\mathrm{~K}$ \\
\hline Heat flux & $20000-114000$ & $\mathrm{~W} \cdot \mathrm{m}^{-2}$ \\
\hline Mole fraction of $\mathrm{SO}_{2}$ & $0.005706-0.027$ & {$[\mathrm{]}$} \\
\hline Pressure & 1 & Bar \\
\hline
\end{tabular}

\section{RESULTS AND DISCUSSION:}

Because of the presence of the injected $\mathrm{SO}_{2}$ near the saturation temperatures, significant mass transfer simultaneously with heat transfer phenomenon occurs, which is the major reason of increasing the heat transfer coefficient. Figs 10 and 11 typically represent the experimental heat transfer coefficient as a function of heat flux.

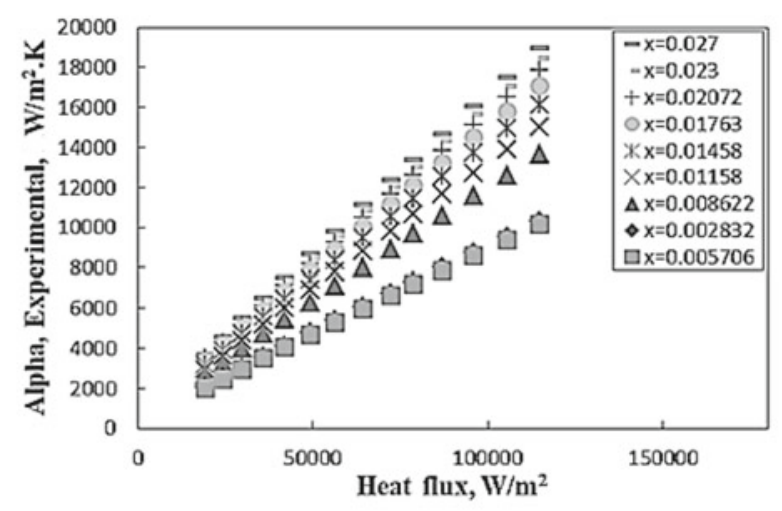

Figure 10. Experimental heat transfer coefficient at different ranges of mole fraction of $\mathrm{SO}_{2}$ into the water

As seen in Fig. 10, increasing the heat transfer coefficient due to increasing the mole fraction of the injected gas may clearly be seen. For better comparison, for different saturation temperatures, experimental heat transfer coefficients are given in Fig. 11:

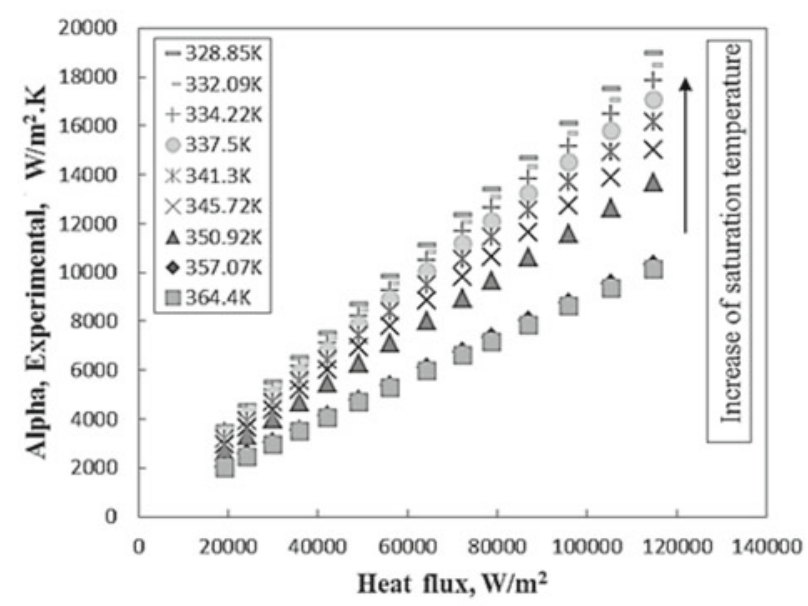

Figure 11. Experimental heat transfer coefficient at various saturation temperature
Likewise, the results demonstrate that nucleation site density is strictly dependent on the heat flux value that has been mathematically taken as an exponential function. Although, by surveying on nucleation sites, it is found that the existing correlations similar to heat transfer coefficient, are not accurate in predicting N/A. Furthermore, a new model may also be proposed for predicting the nucleation site density. Fig 13 typically presents the status of nucleation site density as a function of heat flux during the experiments.

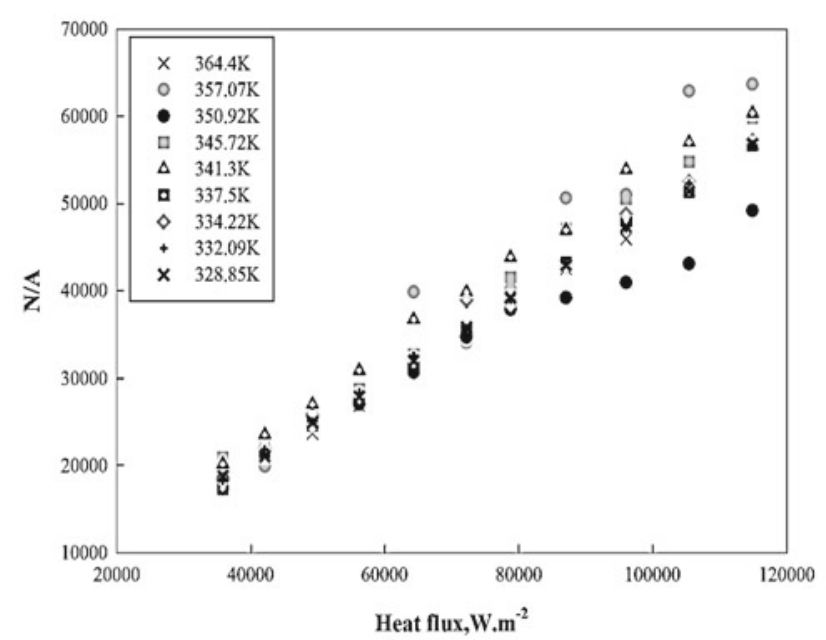

Figure 12. Experimental results of nucleation site density

Bubble diameter has been calculated using the Fritz correlation $^{\mathbf{3 0}}$. Generally, at all the experiment runs, the bubble diameter decreases with increasing the heat fluxes. Fig. 13 typically presents the estimated bubble diameter values as a function of the heat flux and at various saturation temperatures according to the Fritz correlation $^{\mathbf{3 0}}$.

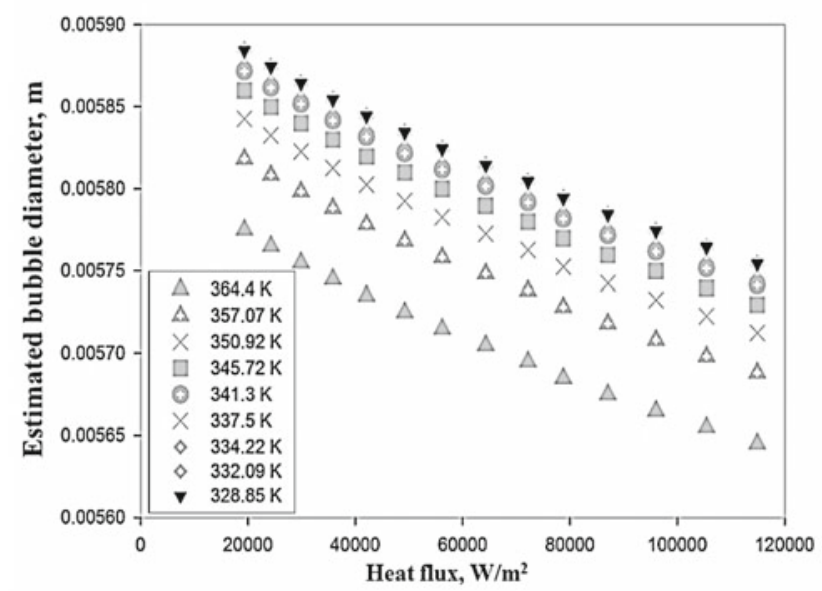

Figure 13. The estimated bubble diameters at various saturation temperatures

It can be concluded that the presence of $\mathrm{SO}_{2}$ gas will influence the bubble diameter and generally increases the bubble diameter. The volume of the captured vapor in the bubble increases the bubble diameter. Fig. 14 represents the induced influence. Different color in Fig. 14 is for different mole fraction (the darker the color, the bigger the bubble diameter). Thus, the effect of gas 
injection appears to increase the numbers of nucleation sites and bubble diameter.



Figure 14. Measured bubble diameter at various heat fluxes and mole fractions of $\mathrm{SO}_{2}$

\section{MODELLING}

\section{A new correlation for heat transfer coefficient}

Although this research was conducted on pure water as the test fluid, in fact, the presence of $\mathrm{SO}_{2}$ creates a binary mixture artificially. With regard to the vapour pressure diagram of $\mathrm{SO}_{2}$, there is a little significant solubility of $\mathrm{SO}_{2}$ in water which may temporary influence the thermo-physical properties. But due to the bubble formation and the local agitation due to the bubble interactions around the heating surface, the dissolved $\mathrm{SO}_{2}$ leaves the liquid phase. Furthermore, because of this phenomenon, the well-known correlations such as Unal, Stephan, jung-Nickel and schlunder were unable to predict the reasonable values of heat transfer coefficient for this particular case. Figs. $15 \mathrm{a}$ and $15 \mathrm{~b}$ show the sim- ple comparison between some well-known correlations and the experimental data at different mole fractions of the injected gas. Table 4 shows some of the well-known correlations for the prediction the pool boiling heat transfer of pure liquids. The result of these correlations has been compared to those obtained experimentally.

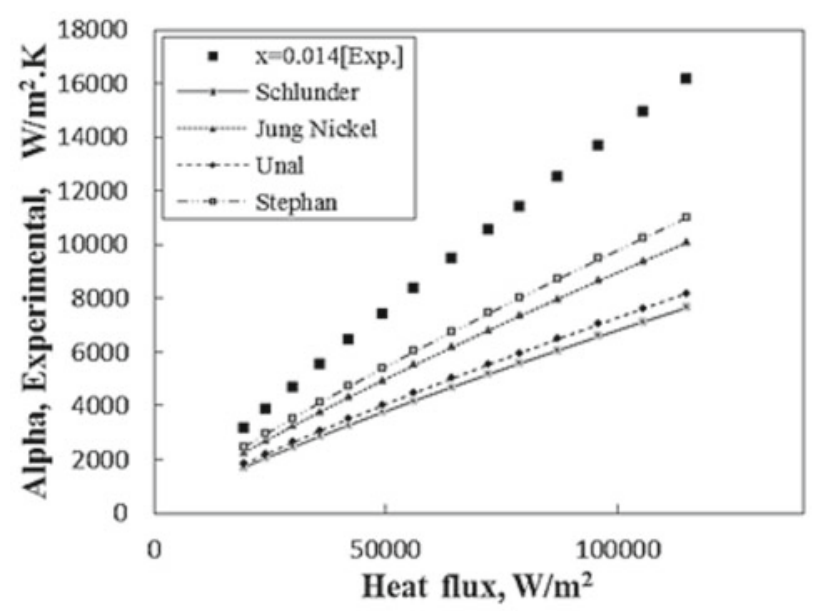

Figure 15a. Comparison of the experimental data and the computed results of the predicted correlations at $\mathrm{x}=0.014$

Table 5 represents the absolute average deviation of the estimated data by the well-known correlations in comparison with the experimental data.

As shown in Figs. 15a and 15b as well as table 6, there is no good agreement between the experimental data and those calculated by the existing correlations, therefore, a new model has been proposed for the prediction of the pool boiling heat transfer coefficient with better prediction in comparison with the earlier existing correlations. Stephan and Körner ${ }^{6}$ proposed a semi-empirical model as Eq. (7):

Table 4. Some of the well-known correlation for pool boiling heat transfer of pure liquids

\begin{tabular}{|c|c|c|}
\hline Author & Correlation & Ref \\
\hline Stephan & $\frac{\alpha}{\alpha_{\text {id }}}=\frac{1}{1+K_{\circ}|y-x|(0.88+0.13 P)}$ & {$[33,34]$} \\
\hline Jungnickel & $\begin{array}{l}\frac{\alpha}{\alpha_{\text {id }}}=\frac{1}{1+K_{\bullet}|y-x|\left(\frac{\rho_{\mathbf{v}}}{\rho_{1}}\right) q^{(0.48+0.1 x)}} \\
\alpha_{i d}=x_{1} \alpha_{1}+x_{2} \alpha_{2}\end{array}$ & {$[33,34]$} \\
\hline- & $\begin{array}{l}\frac{\alpha}{\alpha_{i d}}=\frac{1}{1+(y-x)\left\{1-\exp \left(\frac{-B_{0} q}{\beta_{l} \rho_{l} H_{f g}}\right)\right\}\left(T_{s 1}-T_{s 2}\right) \Delta T_{i d}} \\
B_{0}=1 \quad ; \quad \beta_{l}=2 E-4 \frac{m}{s}\end{array}$ & {$[33,34]$} \\
\hline Unal & $\begin{array}{l}\frac{\alpha}{\alpha_{i d}}=\frac{1}{\left[1+\left(b_{2}+b_{3}\right)\left(1+b_{4}\right)\right]\left[1+b_{5}\right]} \\
b_{\mathbf{2}}=\frac{(1-x) \ln (1.01-x)}{1.01-y}+x \ln \frac{x}{y}+|y-x|^{1.5} \\
\frac{x}{y}=1 \text { for } x=y=0 \\
b_{\mathbf{3}}=0 ; b_{\mathbf{4}}=152 P_{r}^{3.9} b_{\mathbf{5}}=0.92|y-x|^{0.001} P_{r}{ }^{0.66}\end{array}$ & {$[33,34]$} \\
\hline
\end{tabular}




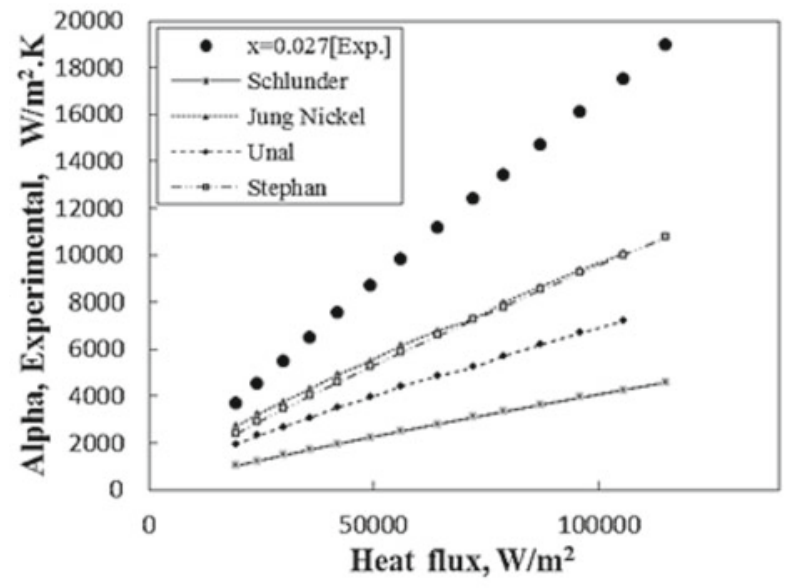

Figure 15b. Comparison of the experimental data and the computed results of the predicted correlations at $\mathrm{x}=0.027$

Table 5. A.A. D \% (Absolute Average Deviation) of estimated data in comparison with experimental data

\begin{tabular}{|c|c|c|c|c|}
\hline $\begin{array}{c}\text { Mole fraction } \\
\text { of } \mathrm{SO}_{2}\end{array}$ & Unal & Stephan & Schlunder & $\begin{array}{c}\text { Jung } \\
\text { Nickel }\end{array}$ \\
\hline $\mathrm{x}=0.014$ & $46.43 \%$ & $28.14 \%$ & $54 \%$ & $33.11 \%$ \\
\hline $\mathrm{x}=0.027$ & $48.46 \%$ & $30.18 \%$ & $58.12 \%$ & $31.16 \%$ \\
\hline $\mathrm{x}=0.005$ & $39.01 \%$ & $27.15 \%$ & $44.11 \%$ & $28.19 \%$ \\
\hline $\mathrm{x}=0.008$ & $26.77 \%$ & $16.44 \%$ & $32.11 \%$ & $19.1 \%$ \\
\hline
\end{tabular}

$\alpha=\frac{\alpha_{i d}}{1+A_{0}(y-x)(0.88+0.12 P)}$

Where $\mathrm{A}_{0}$ is for instance is: 1.5 for glycerin-water, 0.75 for acetone-ethanol, and 3.56 for water-pyridine. For any other mixture, $\mathrm{A}_{0}$ must be obtained through an experiment. But for gas/liquid mixtures this correlation is not adapted very well. Furthermore, this correlation should be modified mathematically for better accuracy in comparison with its original form. Noticeably, $\mathrm{P}$ is the experimental pressure that equals to unity in this investigation. A new model has been proposed according to Eq. (7):

$\alpha=\left[\left(\frac{\alpha_{i d}^{1.11}}{0.92+A_{0}(1-(y-x))(0.88+0.12 P)}\right)^{0.9887}\right]$

In this research, $\mathrm{A}_{0}$, for $\mathrm{SO}_{2} /$ water can be considered 2.35. In these circumstances, better agreement of the experimental data with the computed results is recorded. Figs (16-18) show the results of the new proposed model in comparison with the experimental data at heat fluxes up to $114 \mathrm{~kW} \cdot \mathrm{m}^{-2}$. The $9 \%$ of Deviation in comparison with the experimental data can be considered as Absolute Average Deviation of the proposed correlation.

\section{A new correlation for nucleation site density}

According to the obtained results of nucleation sites counting, N/A is a function of heat flux. This functionality is taken as an exponential function according to Eq. (9):

$\frac{N}{A}=0.8886 \cdot\left(\frac{q}{A}\right)^{0.95031}$

Figs. 20 and 21 typically show the comparison between the new proposed model and the experimental data for the nucleation site density.

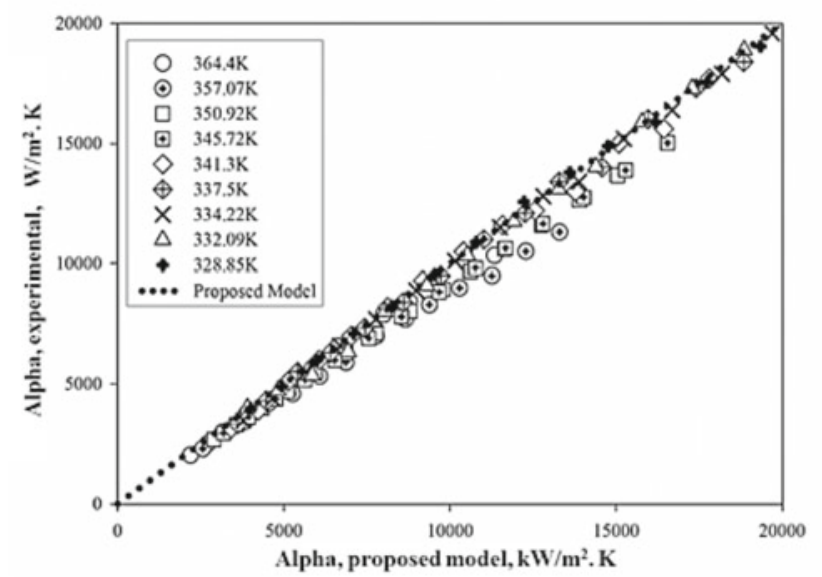

Figure 16. Comparison of the experimental data with the prediction of the new model for heat transfer coefficient

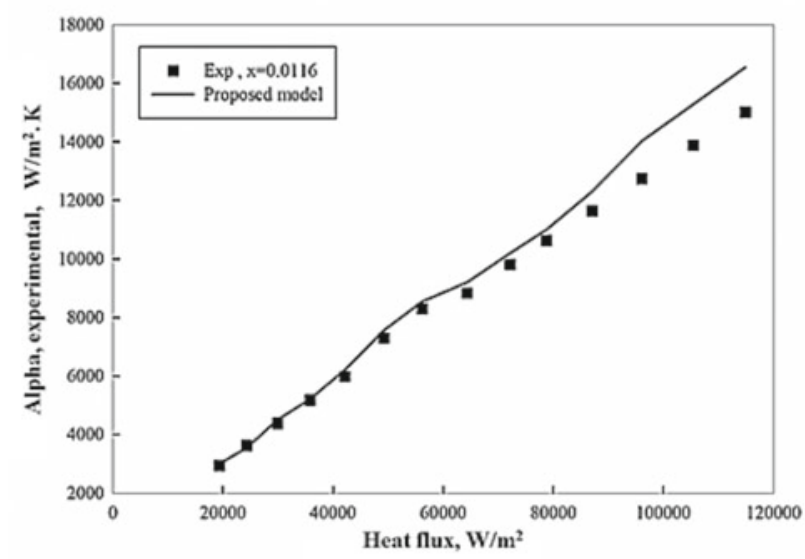

Figure 17. Comparison of the estimated and experimental data of the heat transfer coefficient values at mole fraction $\mathrm{x}=0.0116$

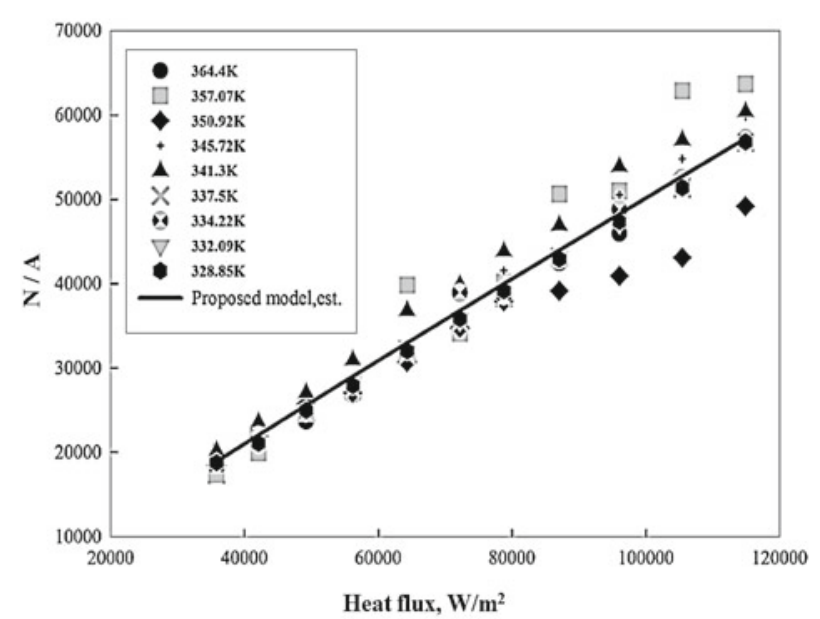

Figure 18. Comparison between the experimental data and the new model prediction for the nucleation side density, N/A

\section{CONCLUSIONS}

Experimental investigations on the effect of gas injection into the pure liquids for enhancing the pool boiling heat transfer coefficient were conducted. Also the effect of operating parameters such as heat flux, mole fraction of injected gas on the heat transfer coefficient, bubble 
diameter and nucleation sites has been experimentally investigated too. The results demonstrated that:

1) Heat flux has a strong effect on the pool boiling heat transfer coefficient such that with increasing the heat flux, the pool boiling coefficient increases.

2) With increasing the rate of gas dissolved into the water, due to the high mass transfer driving force between $\mathrm{SO}_{2}$ captured inside the bubbles and bulk of solution and increasing the local agitations due to the injection process, the pool heat transfer coefficient dramatically increases. Therefore, the significant enhancement of the pool boiling heat transfer coefficient due to the gas injection can be seen.

3) The rate of nucleation sites, bubble generations and bubble diameter dramatically increases when the rate of injection of $\mathrm{SO}_{2}$ increases. However, the bubbles may have been generated artificially due to the injection process and agitations due to the $\mathrm{SO}_{2}$ bubble interactions.

4) The available well-known correlations were unable to predict the heat transfer coefficient and N/A. Therefore, a new modified correlation based on the Schlunder correlation was proposed to predict the heat transfer coefficient accurately. Also a new simple correlation for the nucleation site density has been proposed with A.D.D $\%$ of around $9 \%$.

\section{Nomenclature}

A area, $\mathrm{m}^{2}$

$\mathrm{A}_{0} \quad$ see modeling section (4)

$\mathrm{B}_{0} \quad$ ratio of the interfacial area of heat transfer to the interfacial area of mass transfer

$\mathrm{b}_{1}-\mathrm{b}_{5}$ see Unal equation

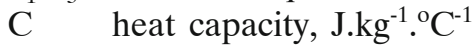

$\mathrm{D}_{\mathrm{AB}}$ diffusivity coefficient, $\mathrm{m}^{2} \cdot \mathrm{s}^{-1}$

$\mathrm{d}_{\mathrm{b}} \quad$ bubble departing diameter, $\mathrm{m}$

$\mathrm{F}_{\mathrm{P}} \quad$ see Gorenflo equation

$\mathrm{F}_{\mathrm{q}} \quad$ see Gorenflo equation

$\mathrm{F}_{\mathrm{WM}}$ see Gorenflo equation

$\mathrm{F}_{\mathrm{WR}}$ see Gorenflo equation

g gravitational acceleration, $\mathrm{m}^{2} \cdot \mathrm{s}^{-1}$

$\mathrm{H}_{\mathrm{fg}}$ heat of vaporization, $\mathrm{j} \cdot \mathrm{kg}^{-1}$

$\mathrm{k}$ thermal conductivity, W.m ${ }^{-1} \cdot{ }^{\circ} \mathrm{C}^{-1}$

$1^{*} \quad$ see Boyko-Krozhilinein literature review

$\mathrm{n}$ see Gorenflo equation

$\mathrm{P}$ pressure, $\mathrm{Pa}$

q Heat, W

$\mathrm{R}_{\mathrm{a}}$ roughness, $\mathrm{m}$

$\mathrm{s}$ distance, $\mathrm{m}$

$\mathrm{T}$ temperature, $\mathrm{k}$

$x \quad$ liquid mass or mole fraction

$y \quad$ vapor mass or mole fraction

\section{Subscripts}

b bulk

c critical

i component

id ideal

1 liquid

o reference

r reduced

s saturated

th thermocouples

$v \quad$ vapor

\author{
Greek symbols \\ $\alpha \quad$ heat transfer coefficient, $\mathrm{W} \cdot \mathrm{m}^{-2} \cdot \mathrm{K}^{-1}$ \\ $\hat{\alpha} \quad$ thermal diffusion, $\mathrm{m}^{2} \cdot \mathrm{s}^{-1}$ \\ $\beta \quad$ mass transfer coefficient, $\mathrm{m} \cdot \mathrm{s}^{-1}$ \\ $\Delta \quad$ difference \\ $\rho$ density, kg.m ${ }^{-3}$ \\ $\sigma \quad$ surface tension, Dyne/cm or somewhere N.m ${ }^{-1}$ \\ $\mu \quad$ viscosity, centipoise, c. $\mathrm{p}$
}

\section{LITERATURE CITED}

1. Vinayak, G. Rao \& Balakrishnan, A.R. (2004). Heat transfer in nucleate pool boiling of multicomponent. Exp. Therm. Fluid Sci. 29, 87-103. Doi: 10.1016/j.expthermflusci.2004.02.001.

2. Gorenflo, D. (1993) Pool boiling. In: VDI Heat Atlas. Doi: 10.1007/978-3-540-77877-6.

3. Stephan, K. \& Abdelsalam, K. (1980). Heat transfer correlation for natural convection boiling Int. J. Heat Mass Tran., 23, 73-87 Doi: 10.1016/0017-9310(80)90140-4.

4. McNelly, M.J. (1953) A Correlation of rates of heat transfers to nucleate boiling of liquids. J. Imperial College Chem. Eng. Soc., 7, 18-34. (doi not found).

5. Boyko-Kruzhilin, (1967), Int. J. Heat Mass Tran., 10, 361 doi: 10.1016/0017-9310(67)90152-4.

6. Mostinski, I.L (1963), Application of the rule of corresponding states for calculation of heat Transfer and critical heat flux. Teploenergetika, 4, 66 (doi not found).

7. Stephan, K. \& Körner, M. (1969), Berechnung des Wärme-übergangs Verdampfender Binärer Flussigkeitgemische., ChmieIng Techn., 41, 409-417. (doi not found).

8. Unal, H.C (1986), Prediction of nucleate pool boiling heat transfer coefficients for binary mixtures, Int. J. of Heat Mass Trans., 29, 637-640. Doi: 10.1016/0017-9310(86)90096-7.

9. Calus, W.F. \& Rice, P. (1972), Pool Boiling: Binary Liquid Mixture, Chem. Eng. Sci., 27(9), 297 Doi: 10.1016/00092509(72)80083-6.

10. Schlünder, E.U. (1983), Heat transfer in nucleate boiling of mixtures, Int. Chem. Eng., 23 (4), 589-599. doi: 10.1016/02552701(86)85014-0.

11. Alavi Fazel, S.A., Jamialahmadi M. \& Safekordi, A. (2008), Experimental investigation in pool boiling heat transfer of pure/binary mixtures and heat transfer correlations., Iranian J. chemistry and Chem. Eng., 27, (3), 135-150.

12. Jungnickel, H., Wassilew, P. \& Kraus, W.E. (1980), Investigations on the heat transfer of boiling binary refrigerant mixtures, International Journal of Refrigeration, 3, 129-133. doi: 10.1016/0140-7007(80)90092-4.

13. Inoue, T., Monde, M. \& Teruya, Y. (2002): Pool boiling heat transfer in binary mixtures of Ammonia/ water. Int. J. of Heat and Mass Trans., 45, 4409-4415 Doi: 10.1016/S00179310(02)00153-9.

14. Thome, J.R. \& Shakir, S. (1987). A new correlation for nucleate boiling of binary mixtures, AIChE Symposium Series, 83, 46-51.

15. Fujita, Y. \& Tsutsui, M. (1994). Heat transfer in nucleate boiling of binary mixtures, Int. J. Heat Mass Transfer, 37, 291-302. Doi: 10.1016/0017-9310(94)90030-2.

16. Fujita, Y. \& Tsutsui, M. (1996). Convective flow boiling of binary mixtures in a vertical tube in convective Flow Boiling, Taylor \& Francis, Washington, 259-264.

17. Jamialahmadi M., Helalizadeh A., Müller-Steinhagen H. (2004). Pool boiling heat transfer to electrolyte solutions, Int. J. Heat and Mass Transfer, Vol. 47, 729-742 Doi: 10.1016/j. ijheatmasstransfer.2003.07.025.

18. Alavi Fazel, A.S., Jamialahmadi, M. \& Safekordi, A.A.(2009). Pool Boiling Heat Transfer in Dilute Water/ Triethyleneglycol Solutions, Chinese J. Chem. Eng., 17(4) Doi: 10.1016/S1004-9541(08)60244-X. 
19. Peyghambarzadeh, S.M., Jamialahmadi M., Alavi Fazel S.A., Azizi S., (2009), saturated nucleate boiling to binary and ternary mixtures on horizontal cylinder, Exp. Therm. Fluid Sci., 33 (5), 903-911. Doi: 10.1016/j.expthermflusci.2009.03.006.

20. Joback, K.G. (1984), M.S. Thesis in Chemical Engineering, Massachusetts Institute of Technology, Cambridge, Mass., June.

21. Spencer, C.F. \& Danner, R.P. (1971), J. Chem. Eng. Data, 1972, Vol. 17 p. 236 Li, C. C., Can. J. Chem. Eng., , 19, 709. Doi: 10.1081/LFT-200028050.

22. Baroncini, C. (1981), Int. J. Thermophys., 2, 21. (doi not found).

23. Filippov, L.P. (1955), Vest. Mosk. Univ., Ser. Fiz. Mat. Estestv. Nauk, 10, 30.

24. Filippov, L.P. \& Novoselova, N.S. (1955), Sugden, Vest. Mosk. Univ., Ser. Fiz. Mat. Estestv.Nauk, 10, 37.

25. Ruicka-Domalski method, (2008), Thermodynamic properties of gases and liquids. Chapter 6- Estimate the liquid heat capacity of pure liquids by means of contribution method. Doi: 10.1016/0378-3812(82)85001-2.

26. Coulson, J.M. \& Richardson, J.F. (1977). Chemical Engineering, 1, Pergamon Press, 268-276. Doi: 10.1016/S00151882(96)90353-5.

27. Hines, A.L. \& Maddox, R.N. (1985), "Mass transfer fundamentals and applications", Prentice-Hall, Englewood, NJ, Doi: 10.1002/aic.690310926.

28. Fujita, Y. \& Bai, Q (2002). Bubble dynamics and heat transfer in mixture boiling, In: J. Taine et al., Proc. 12th Int. Heat Transfer Conf., Elsevier SAS, Grenoble.

29. Wadekar, V.V. (1994): Convective heat transfer of binary mixtures in annular two-phase low, in: Proceedings of the 10th Int. Heat Transfer Conf., Brighton, 7, 557-562. Doi: 10.1016/ S0017-9310(00)00210-6.

30. Fritz, W. (1935), Berechunung des maximal volumens von Dampfblasen, Phys. Z., 36, 379-384. Doi: /10.1016/00179310(65)90128-6.

31. 13.NIST-TRC-Thermodynamics Research Center, U. S. National Institute of Standards and Technology, Boulder, CO (formerly The Texas A\&M University System, College Station, TX).

32. 14.TDC-Thermodynamics Data Center, the Institute of Coal Chemistry (Gliwice) and the Institute of Physical Chemistry and property (Warsaw) of the Polish Academy of Sciences, Poland.

33. Sarafraz, M.M., Peyghambarzadeh, S.M., Alavifazel, S.A. (2012), Enhancement of nucleate pool boiling heat transfer to dilute binary mixtures using endothermic chemical reactions around the smoothed horizontal cylinder (48) 10 1755-1765, DOI: $10.1007 / \mathrm{s} 00231-012-1019-5$.

34. Sarafraz, M.M. (2012), Nucleate pool boiling of aqueous solution of citric acid on a smoothed horizontal cylinder, 48, 4 611-619, DOI: 10.1007/s00231-011-0910-9.

35. Sarafraz, M.M. \& Peyghambarzadeh, S.M. (2012). Influence of thermodynamic models on the prediction of pool boiling heat transfer coefficient of dilute binary mixtures, 39, 1303-1310. http://dx.doi.org/10.1016/j.icheatmasstransfer.2012.06.020. 